\title{
Involvement of c-Fos in fenretinide-induced apoptosis in human ovarian carcinoma cells
}

\author{
V Appierto ${ }^{*, 1}$, MG Villani ${ }^{1}$, E Cavadini ${ }^{1}, \mathrm{R}$ Lotan $^{2}$, C Vinson $^{3}$ and \\ F Formelli $^{1}$ \\ ${ }^{1}$ Chemopreventive Unit, Department of Experimental Oncology, Istituto \\ Nazionale per lo Studio e la Cura dei Tumori, Milan, Italy; \\ 2 Department of Thoracic and Head and Neck Medical Oncology, MD Anderson \\ Cancer Center, Houston, TX, USA; \\ ${ }^{3}$ Laboratory of Metabolism, National Institutes of Health, Bethesda, MD, USA \\ * Corresponding author: V Appierto, Istituto Nazionale per lo Studio e la Cura dei \\ Tumori, via Venezian 1, 20133 Milan, Italy. Tel. + 3902 23902203; \\ Fax + 39 -02 23902692; E-mail: valentina.appierto@ istitutotumori.mi.it
}

Received 09.4.03; revised 17.9.03; accepted 09.10.03; published online 28.11.03 Edited by Dr M Piacentini

\section{Abstract}

Fenretinide (HPR), a synthetic retinoid that exhibits lower toxicity than other retinoids, has shown preventive and therapeutic activity against ovarian tumors. Although the growth inhibitory effects of HPR have been ascribed to its ability to induce apoptosis, little is known about the molecular mechanisms involved. Since the proto-oncogene c-Fos has been implicated in apoptosis induction, we analyzed its role in mediating HPR response in a human ovarian carcinoma cell line (A2780) sensitive to HPR apoptotic effect. In these cells, HPR treatment caused induction of c-Fos expression, whereas such an effect was not observed in cells made resistant to HPR-induced apoptosis (A2780/HPR). Moreover, in a panel of other human ovarian carcinoma cell lines, c-Fos inducibility and HPR sensitivity were closely associated. Ceramide, which is involved in HPR-induced apoptosis, was also involved in cFos induction because its upregulation by HPR was reduced by fumonisin $B_{1}$, a ceramide synthase inhibitor. The causal relationship between $\mathrm{C}$-Fos induction and apoptosis was established by the finding of an increased apoptotic rate in cells overexpressing $c$-Fos. Similarly to that observed for c-Fos expression, HPR treatment increased c-Jun expression in HPR-sensitive but not in HPR-resistant cells, suggesting the involvement of the transcription factor activating protein 1 (AP-1) in HPR-induced apoptosis. In gene reporter experiments, HPR stimulated AP-1 transcriptional activity and potentiated the AP-1 activity induced by 12-tetradecanoylphorbol 13-acetate. Furthermore, inhibition of AP-1 DNA binding, by transfecting A2780 cells with a dominantnegative Fos gene, caused decreased sensitivity to HPR apoptotic effects. Overall, the results indicate that c-Fos plays a role in mediating HPR-induced growth inhibition and apoptosis in ovarian cancer cells and suggest that c-Fos regulates these processes as a member of the AP-1 transcription factor.

\author{
Cell Death and Differentiation (2004) 11, 270-279. doi:10.1038/ \\ sj.cdd. 4401349 \\ Published online 28 November 2003
}

Keywords: retinoids; fenretinide; c-Fos, AP-1; apoptosis

\begin{abstract}
Abbreviations: 13-cis RA, 13-cis-retinoic acid; AP-1, activating protein 1; C2Cer, $\mathrm{N}$-acetylsphingosine; CD437, 6-[3-adamantyl4-hydroxyphenyl]-2-naphthalene carboxylic acid; GFP, green fluorescent protein; HPR, fenretinide or $\mathrm{N}$-(4-hydroxyphenyl)retinamide; $\mathrm{FB}_{1}$, fumonisin $\mathrm{B}_{1}$; $\mathrm{PBS}$, phosphate-buffered saline; $\mathrm{RA}$, all-trans-retinoic acid; RAR, retinoic acid receptor; RXR, retinoid $X$ receptor; ROS, reactive oxygen species; RT-PCR, reverse transcription polymerase chain reaction; TPA, 12tetradecanoylphorbol 13-acetate; TUNEL, terminal dUTP nickend labeling
\end{abstract}

\section{Introduction}

Retinoids are natural and synthetic derivatives of vitamin A that play an important role in different biological processes including cell proliferation, differentiation, and apoptosis. ${ }^{1}$ These compounds have been shown to have antitumor activity in several experimental models and they are being evaluated as therapeutic and preventive agents for malignant diseases. ${ }^{2}$ Fenretinide or $\mathrm{N}$-(4-hydroxyphenyl)retinamide (HPR) is a retinoic acid (RA) derivative that has shown lower toxicity than other retinoids while maintaining antitumor activity against various tumor types. ${ }^{3}$ HPR has been proven to be active in the prevention and treatment of different tumors in animals and, by inducing apoptosis, it has shown growth inhibitory effects against a variety of human tumor cell lines including ovarian tumor cells. ${ }^{4,5}$ In humans, this retinoid has already shown efficacy in oral leukoplakia, ${ }^{6}$ lichen planus, ${ }^{7}$ and actinic keratoses, ${ }^{8}$ and has shown a potential for preventing ovarian cancer $^{9,10}$ and breast cancer in premenopausal women. ${ }^{11}$ However, the underlying mechanism(s) of action of HPR is still not fully understood. Some studies suggest that its apoptotic activity is mediated through retinoic acid receptor (RAR) and retinoid $X$ receptor $(R X R)$ signaling. ${ }^{5,12-14}$ Other studies have reported that apoptosis in response to HPR primarily occurs by a receptor-independent mechanism, which is accompanied by generation of reactive oxygen species (ROS), ${ }^{15,16}$ alteration of mitochondrial membrane potential, ${ }^{17,18}$ a decrease in $\mathrm{Bcl}-2$ expression, ${ }^{19}$ or an increase in ceramide levels. ${ }^{20-22}$

The proto-oncogene c-Fos encodes a nuclear DNA binding phosphoprotein that dimerizes with the gene product of $c$-Jun to form the transcription factor activating protein 1 (AP-1). AP1 converts extracellular signals into changes in the expression of specific target genes, which harbor the AP-1 DNA binding site(s) in their promoter regions. ${ }^{23}$ As a member of AP-1, CFos protein has been implicated mainly in signal transduction, cell differentiation, and proliferation. ${ }^{23}$ Several studies have suggested that c-Fos protein may be a mediator of apoptotic 
cell death induced by antiproliferative conditions. An increase in c-Fos expression in conjunction with apoptosis has been shown in different cell types after exposure to drugs, chemical agents, or growth factor deprivation. ${ }^{24}$ Moreover, in vitro studies have demonstrated a functional involvement of c-Fos protein in apoptosis since its overexpression actively induced apoptosis in susceptible cell lines. ${ }^{25-27}$ Further evidence suggesting a proapoptotic role for c-Fos comes from in vivo observations. c-Fos has been shown to positively regulate apoptosis during development, tissue remodeling, and stress responses in various tissues. ${ }^{28}$

The present study investigated the involvement of c-Fos in HPR-induced apoptosis in ovarian tumor cells. We previously showed that the human ovarian carcinoma cell line A2780 is very sensitive to apoptosis induction by HPR treatment, ${ }^{4}$ and that A2780 cells become resistant to HPR action (A2780/ HPR) when continuously exposed to the retinoid. ${ }^{29}$ We also reported that HPR was able to induce ceramide levels in sensitive but not in resistant cells. ${ }^{22}$ Using A2780 and A2780/ HPR cells and a panel of other human ovarian cancer cell lines, we examined the effects of HPR treatment on c-Fos expression to determine the role of the proto-oncogene in HPR-induced apoptosis. Our findings indicated that c-Fos inducibility and HPR-induced apoptosis are closely associated. We analyzed the role of ceramide in HPR-induced upregulation of c-Fos expression and we found that elevation of ceramide levels in A2780 cells might be responsible for the gene induction. The functional involvement of c-Fos in apoptosis was then investigated in A2780 overexpressing cFos. Furthermore, we addressed the question of whether cFos carries out its proapototic action in response to HPR as a member of AP-1, and we demonstrated that AP-1 is involved in HPR antiproliferative and apoptotic effects.

\section{Results}

\section{HPR effect on c-Fos expression in A2780 and A2780/HPR cells}

The potential involvement of c-Fos in the apoptotic effect of HPR was investigated in A2780, a human ovarian carcinoma cell line very sensitive to HPR, ${ }^{4}$ and in A2780/HPR, an HPRresistant cell line generated after continuous exposure to the drug. ${ }^{29}$ As shown in Figure 1a, treatment of A2780 cells with 5 and $10 \mu \mathrm{M}$ HPR for $24 \mathrm{~h}$ resulted in a dose-dependent induction of apoptosis, as measured by the terminal dUTP nick-end labeling (TUNEL) assay. c-Fos mRNA expression, analyzed by reverse transcription polymerase chain reaction (RT-PCR) in A2780 cells, showed that A2780 cells constitutively expressed c-Fos mRNA, and that HPR treatment increased its expression (Figure $1 \mathrm{~b}$ and $\mathrm{c}$ ). Specifically, treatment with 1,5 , and $10 \mu \mathrm{M}$ HPR for $24 \mathrm{~h}$ caused a dosedependent increase in c-Fos mRNA (10-fold after treatment with $10 \mu \mathrm{M}$ HPR) (Figure 1b). Time-course analysis showed no change in c-Fos mRNA level after $6 \mathrm{~h}$ of treatment with $5 \mu \mathrm{M}$ HPR. However, after $24 \mathrm{~h}$ of HPR exposure, c-Fos mRNA began to increase, and its augmentation was time dependent up to $48 \mathrm{~h}$ (14-fold) (Figure 1c). Induction of c-Fos in A2780 cells due to HPR treatment was also observed at a protein level (six-fold), as demonstrated by Western blot
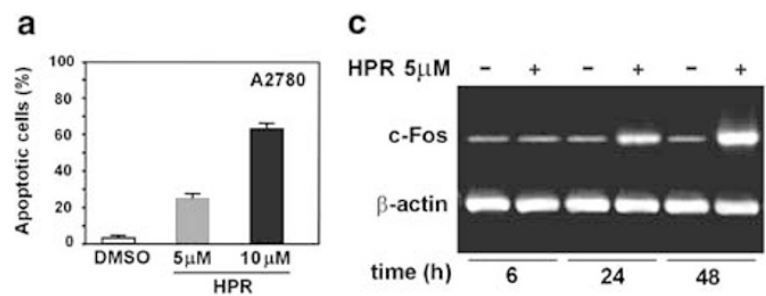

b

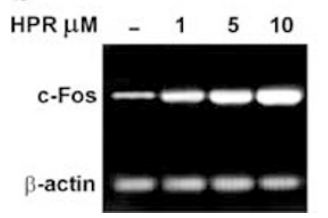

d

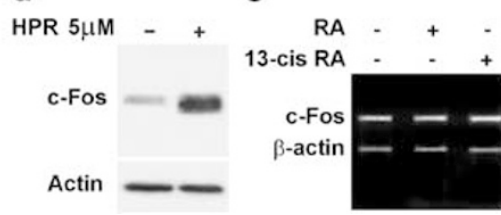

Figure $1 \mathrm{c}$-Fos upregulation in cells sensitive to HPR-induced apoptosis (A2780). (a) Detection of HPR-induced apoptosis in A2780 cells. At 1 day after seeding, cells were treated with 5 and $10 \mu \mathrm{M} \mathrm{HPR}$ for $24 \mathrm{~h}$, and apoptosis was evaluated by the TUNEL assay. Data represent the means \pm S.D. of three independent experiments. (b) RT-PCR assay to determine the expression of cFos in A2780 cells following addition of 1, 5 and $10 \mu \mathrm{M} \mathrm{HPR}$ for $24 \mathrm{~h}$. In all, $2 \mu \mathrm{g}$ of total RNA was retrotranscribed, and the gene sequences for $\mathrm{c}$-Fos and $\beta$-actin, used as internal standard, were coamplified in the same reaction. (c) RT-PCR assay to determine the expression of c-Fos in A2780 cells following addition of $5 \mu \mathrm{M}$ HPR for 6,24 and $48 \mathrm{~h}$. A total of $2 \mu \mathrm{g}$ of total RNA was retrotranscribed, and the gene sequences for $c$-Fos and $\beta$-actin, used as internal standard, were coamplified in the same reaction. (d) Western analysis for c-Fos expression in A2780 following addition of $5 \mu \mathrm{M}$ HPR for $24 \mathrm{~h}$. As a control for loading, the blot was incubated with actin antibody. (e) RT-PCR assay to determine the expression of c-Fos in A2780 cells following addition of $5 \mu \mathrm{M} \mathrm{RA}$ or $5 \mu \mathrm{M} 13-c i s$ RA for $24 \mathrm{~h}$. In all, $2 \mu \mathrm{g}$ of total RNA was retrotranscribed, and the gene sequences for $c$-Fos and $\beta$-actin, used as internal standard, were coamplified in the same reaction

analysis at $24 \mathrm{~h}$ (Figure 1d). c-Fos mRNA expression was also analyzed in A2780 cells treated for $24 \mathrm{~h}$ with $5 \mu \mathrm{M}$ RA or $5 \mu \mathrm{M}$ 13-cis-retinoic acid (13-cis-RA), two retinoids we previously demonstrated to have no growth inhibitory effects on A2780 cells. ${ }^{29} \mathrm{C}$-Fos expression was not affected by the two retinoids (Figure 1e).

In order to understand whether the observed HPR-induced upregulation of c-Fos was related to sensitivity of the A2780 cell line to HPR, the analysis of c-Fos expression was extended to A2780/HPR, an HPR-resistant cell line. As we previously reported, ${ }^{29}$ the A2780/HPR cell line was generated by in vitro incubation of A2780 cells with increasing concentrations of HPR. Figure 2a shows that A2780/HPR cells were resistant to HPR-induced apoptosis, as determined by the TUNEL assay. A 24-h treatment of A2780/HPR cells with 5 and $10 \mu \mathrm{M}$ HPR did not result in an augmentation of apoptosis (Figure 2a), which was instead observed in A2780 cells. Contrary to that found in A2780 cells, treatment of A2780/HPR cells with 5 and $10 \mu \mathrm{M}$ HPR for $24 \mathrm{~h}$ did not increase the level of c-Fos mRNA expression (Figure $2 b$ ). Such findings suggested an association between HPRinduced c-Fos upregulation and the ability of the retinoid to induce apoptosis.

\section{HPR sensitivity and c-Fos induction in SKOV-3, OVCA-432, OAW-42, and IGROV-1 cells}

To evaluate whether the upregulation of c-Fos and its association with HPR sensitivity were general features of 
ovarian cancer cells, the analysis of c-Fos expression was extended to a panel of other human ovarian cancer cells. The effect of HPR on the proliferation of SKOV-3, OVCA-432, OAW-42, and IGROV-1 human ovarian carcinoma cell lines was evaluated $24 \mathrm{~h}$ after exposure to the drug. As shown in Figure $3 a$, cell sensitivity to HPR was similar for the four cell lines. Overall, these cells resulted more resistant to HPR than A2780 cells at all tested doses, and $20-60 \%$ cell growth inhibition was achieved with the highest tested dose of $15 \mu \mathrm{M}$ HPR. At variance with that observed in A2780 cells, treatment of SKOV-3, OVCA-432, OAW-42, and IGROV-1 cells with 5 and $10 \mu \mathrm{M}$ HPR for $24 \mathrm{~h}$ did not increase the level of c-Fos mRNA expression (Figure 3b). However, $15 \mu \mathrm{M}$ HPR caused c-Fos upregulation in all cell lines, indicating that effective doses of HPR cause c-Fos upregulation. Owing to their

a

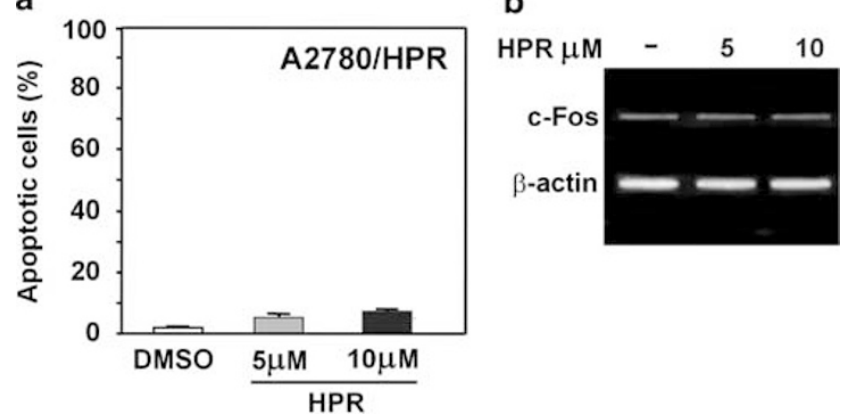

Figure 2 Lack of $\mathrm{C}$-Fos upregulation in cells resistant to HPR-induced apoptosis (A2780/HPR). (a) Detection of HPR-induced apoptosis in A2780/HPR cells. At 1 day after seeding, cells were treated with 5 and $10 \mu \mathrm{M} \mathrm{HPR}$ for $24 \mathrm{~h}$, and apoptosis was evaluated by the TUNEL assay. Data represent the means \pm S.D. of three independent experiments. (b) RT-PCR to determine the expression of c-Fos in A2780/HPR cells following addition of HPR 5 and $10 \mu \mathrm{M}$ for $24 \mathrm{~h}$. A total of $2 \mu \mathrm{g}$ of total RNA was retrotranscribed, and the gene sequences for c-Fos and $\beta$-actin, used as internal standard, were coamplified in the same reaction
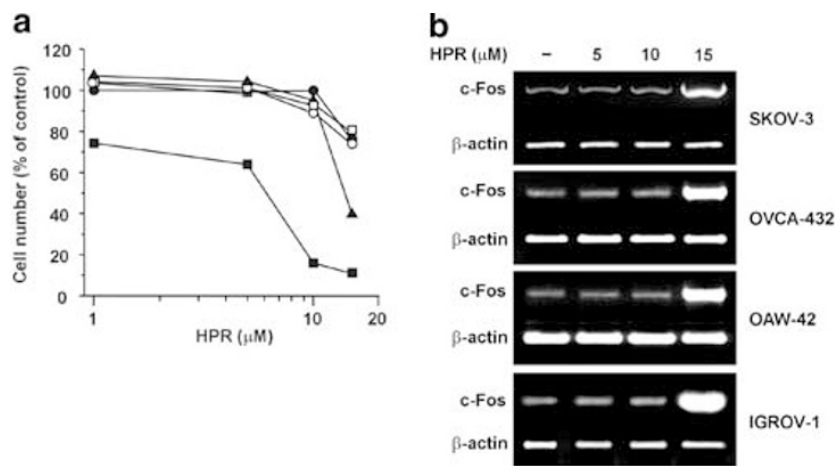

Figure 3 HPR sensitivity and c-Fos upregulation in SKOV-3, OVCA-432, OAW-42, and IGROV-1 cell lines. (a) Growth inhibitory effect of HPR on SKOV-3 (-), OVCA-432 (O), OAW-42 ( $\square$ ), IGROV-1 (A), and A2780 (ם) cells. Cells were treated with HPR $24 \mathrm{~h}$ after seeding, and surviving cell number was evaluated 1 day later. Data represent the means of three independent experiments. The S.D. never exceeded $15 \%$. (b) RT-PCR assay to determine the expression of c-Fos in SKOV-3, OVCA-432, OAW-42, and IGROV-1 cells following addition of 5,10 , and $15 \mu \mathrm{M} \mathrm{HPR}$ for $24 \mathrm{~h}$. A total of $2 \mu \mathrm{g}$ of total RNA was retrotranscribed, and the gene sequences for c-Fos and $\beta$-actin, used as internal standard, were coamplified in the same reaction highest HPR sensitivity, A2780 cells were chosen for additional analysis.

\section{Role of the elevation of ceramide levels on c-Fos upregulation}

We have recently shown that HPR is able to induce an increase in cellular ceramide levels in A2780 cells but not in A2780/HPR cells. ${ }^{22}$ Moreover, induction of c-Fos expression following ceramide treatment has been reported in different cell systems. ${ }^{30-32}$ We hypothesized that elevation of ceramide levels in A2780 cells might be responsible for c-Fos induction. A2780 cells exposed to 10 and $20 \mu \mathrm{M} \mathrm{N}$-acetylsphingosine (C2Cer) for $24 \mathrm{~h}$ showed a dose-dependent induction of c-Fos mRNA expression (Figure 4a). We then analyzed the effects of the ceramide synthase inhibitor $F B_{1}$ on HPR-induced upregulation of c-Fos expression in A2780 cells. Figure $4 \mathrm{~b}$ shows that cotreatment of cells with $5 \mu \mathrm{M} \mathrm{HPR}$ and $50 \mu \mathrm{M} \mathrm{FB}$ reduced the upregulation of c-Fos mRNA relative to that induced by $5 \mu \mathrm{M}$ HPR alone. Cells cotreated with HPR and $\mathrm{FB}_{1}$ also showed a reduction of apoptosis by approximately $50 \%$ compared to cells treated with HPR alone (Figure 4c). The data suggested that HPR-induced elevation of ceramide levels in A2780 cells might be responsible for cFos induction.

\section{Overexpression of c-Fos-green fluorescent protein (GFP) by transient transfection and its effect on apoptosis}

To establish a causal relationship between the increase in cFos expression and apoptosis induction in A2780 cells, we determined whether direct overexpression of c-Fos in the absence of external stimuli could cause apoptosis. c-Fos expression levels were increased by transient transfection with a GFP-tagged c-Fos vector (Figure 5a). Cells transfected
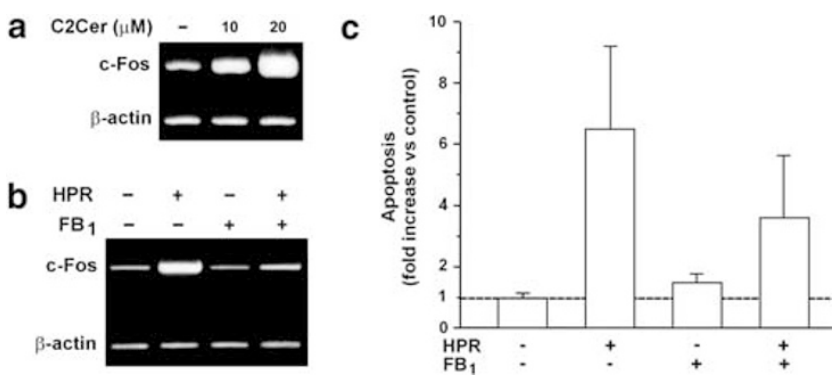

Figure 4 Ceramide effects on c-Fos expression and HPR-induced apoptosis. (a) RT-PCR assay to determine the expression of c-Fos in A2780 cells following addition of 10 and $20 \mu \mathrm{M} \mathrm{C} 2 \mathrm{Cer}$ for $24 \mathrm{~h}$. In all, $2 \mu \mathrm{g}$ of total RNA was retrotranscribed, and the gene sequences for $\mathrm{c}$-Fos and $\beta$-actin, used as internal standard, were coamplified in the same reaction. (b) RT-PCR assay to determine the expression of c-Fos in A2780 cells following addition of $5 \mu \mathrm{M} \mathrm{HPR}, 50 \mu \mathrm{M}$ $\mathrm{FB}_{1}$, or the two agents together for $24 \mathrm{~h}$. A total of $2 \mu \mathrm{g}$ of total RNA was retrotranscribed, and the gene sequences for $\mathrm{c}$-Fos and $\beta$-actin, used as internal standard, were coamplified in the same reaction. (c) Detection of HPR-induced apoptosis in the absence or presence of $\mathrm{FB}_{1}$ in $\mathrm{A} 2780$ cells. At 1 day after seeding, cells were treated with $5 \mu \mathrm{M} \mathrm{HPR}, 50 \mu \mathrm{M} \mathrm{FB}_{1}$, or the two agents together for $24 \mathrm{~h}$, and apoptosis was evaluated by the ELISA assay. Data represent the means \pm S.D. of three independent experiments 

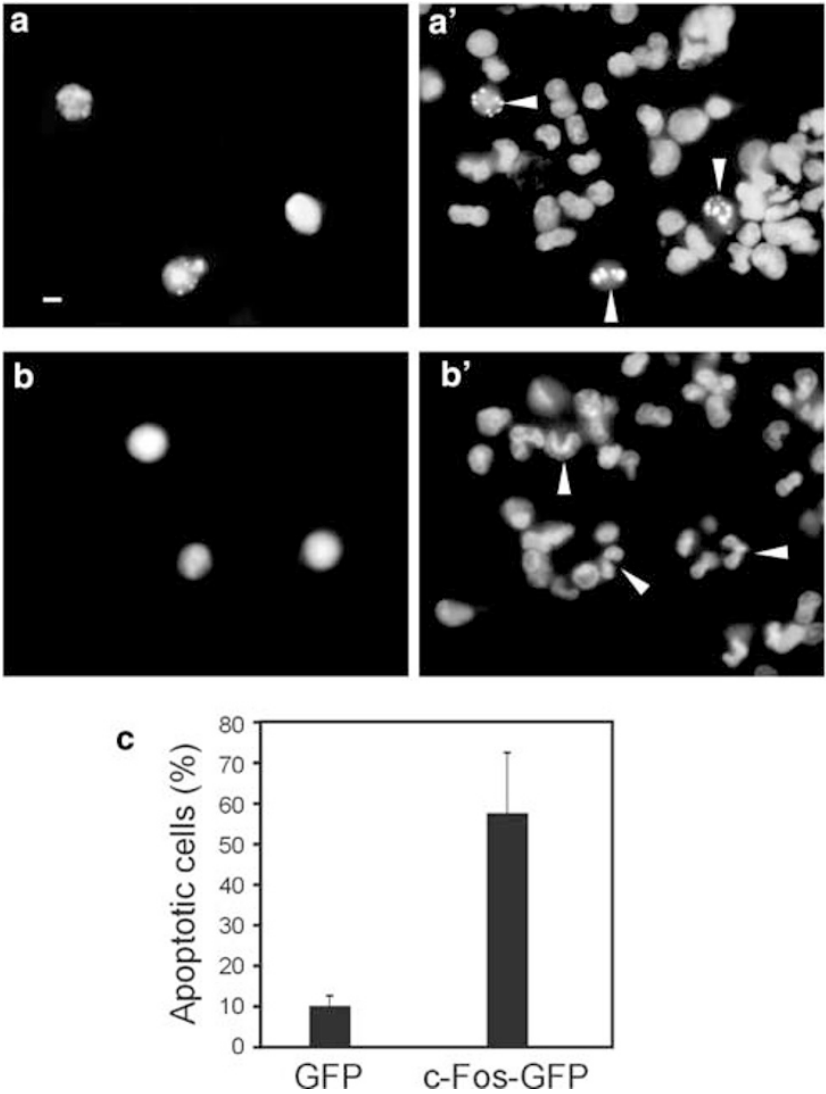

Figure 5 Apoptosis increase in A2780 cells transiently transfected with GFP-CFos. A2780 cells were transiently transfected with GFP-c-Fos (a) or GFP alone as control (b). After $72 \mathrm{~h}$, GFP-c-Fos and control cells were stained with Hoechst 33342 ( $\mathbf{a}^{\prime}$ and $\mathbf{b}^{\prime}$, respectively), and nuclear morphology was examined with a fluorescent microscope. Cells of interest are marked by arrows. Cells with condensed and fragmented nuclei were identified and scored as apoptotic cells. The scale bar represents $10 \mu \mathrm{m}$. (c) Apoptosis was represented as percentage of apoptotic cells per 100 green fluorescent cells in two different smears. Data represent the mean \pm S.D. of three independent experiments

with a vector coding for GFP were used as control (Figure 5b). At 3 days after transfection, nuclear fragmentation and chromatin condensation were monitored in green fluorescent cells by staining cells with Hoechst 33342 . Figure $3 a^{\prime}$ and $b^{\prime}$ show nuclear staining of GFP-c-Fos and GFP-transfected cells, respectively. GFP-c-Fos-overexpressing cells showed an approximately five-fold increase in apoptosis relative to control cells transfected with GFP alone (Figure 5c). These findings strongly suggested a role for c-Fos in the onset of apoptosis in A2780 cells.

\section{Overexpression of c-Fos by stable transfection and its effect on cell growth and apoptosis}

To exclude that apoptosis due to overexpression of GFP-cFos might be a consequence of overloading the nucleus with the GFP instead of a specific function of c-Fos per se, an expression vector containing the full-length c-Fos cDNA was stably transfected into A2780 cells. After hygromycin selection, resistant clones were picked up and individually cultured. a

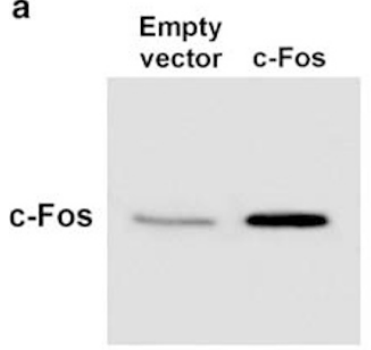

Actin

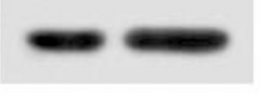

b

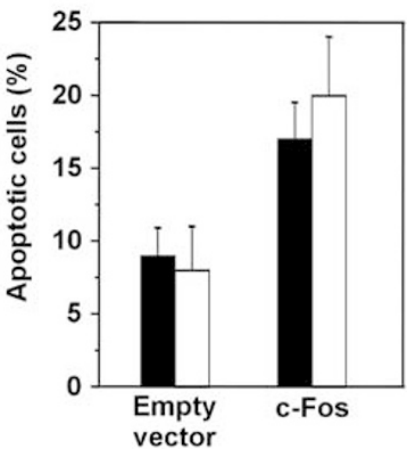

Figure 6 Apotosis increase in A2780 cells stably transfected with c-Fos. (a) Western blot analysis for c-Fos expression in A2780 cells transfected with c-Fos and in A2780 control cells (empty vector). As a control for loading, the blot was incubated with actin antibody. (b) Detection of apoptosis in A2780 cells transfected with c-Fos and in A2780 control cells (empty vector). At 3 days after seeding, the cells were harvested and apoptosis was evaluated by nuclear staining with Hoechst 33342 (black columns) and by the TUNEL assay (white columns). Data represent the means \pm S.D. of two independent experiments

Unlike mock clones (transfected with the empty vector and used as control cells), isolated c-Fos clones were unable to effectively proliferate and, after two or three passages, they died. To overcome this inconvenience, the hygromycinresistant clones were pooled together and a heterogeneous nonclonal cell population was isolated. c-Fos expression, analyzed by Western blot, confirmed the expected c-Fos overexpression (9.5-fold relative to control) (Figure 6a). Microscopic observations revealed that transfection with $\mathrm{c}$ Fos led to a massive detachment of cells from the culture dish compared with cells transfected with the empty vector: $72 \mathrm{~h}$ after seeding, c-Fos transfectants showed an approximate $60 \%$ reduction in adherent cell number relative to mock transfectants (data not shown). Analysis of apoptosis after staining with Hoechst 33342 and by TUNEL assay (Figure 6b) showed a higher percentage of apoptotic cells in c-Fostransfected cells compared with mock cells.

\section{HPR effect on c-Jun expression in A2780 and in A2780/HPR cells}

Since c-Fos regulates apoptosis as a component of AP-1 transcription factor, typically dimerizing with c-Jun, ${ }^{23}$ we also examined the effects of HPR on c-Jun expression in HPRsensitive and HPR-resistant cells. Treatment with $5 \mu \mathrm{M} \mathrm{HPR}$ for $24 \mathrm{~h}$ caused induction of c-Jun mRNA (1.8-fold) in A2780 cells (Figure 7a), whereas such an effect was not observed in A2780/HPR cells (Figure 7b), even in the presence of a higher HPR concentration $(10 \mu \mathrm{M})$ (Figure $7 \mathrm{~b})$, thus suggesting a possible involvement of AP-1 in cellular response to HPR.

\section{Effect of HPR on AP-1 activity}

Following the observation of HPR induction of both members of AP-1 transcription factor in sensitive cells, we then explored whether HPR affected AP-1 transcriptional activity. A2780 


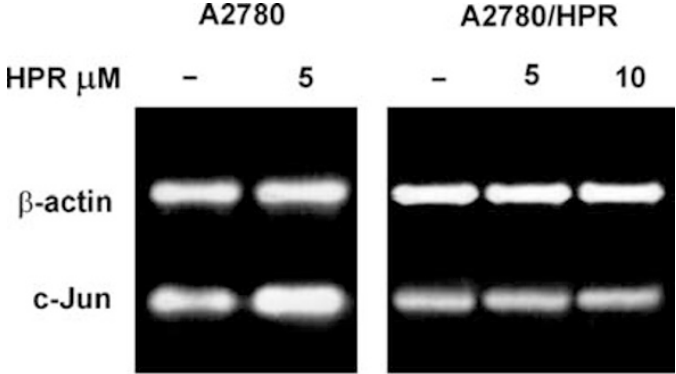

Figure 7 c-Jun upregulation by HPR in A2780 but not in A2780/HPR cells. RTPCR to determine the expression of c-Jun in A2780 cells following addition of $5 \mu \mathrm{M}$ HPR for $24 \mathrm{~h}$, and in A2780/HPR cells following addition of 5 and $10 \mu \mathrm{M}$ HPR for $24 \mathrm{~h}$. In all, $2 \mu \mathrm{g}$ of total RNA was retrotranscribed, and the gene sequences for c-Jun and $\beta$-actin, used as internal standard, were coamplified in the same reaction

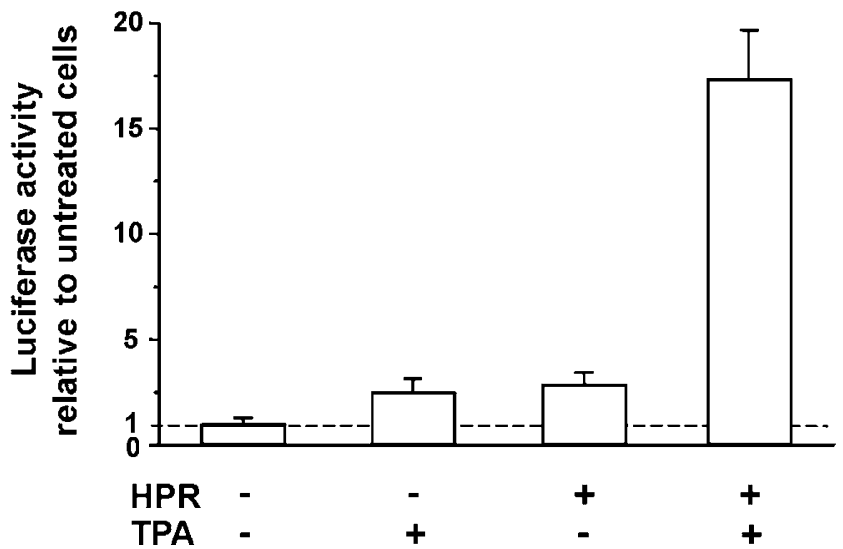

Figure 8 Transactivation of AP-1 activity by HPR. AP-1-dependent luciferase assay in A2780 cells. A2780 cells were transfected with pAP1-Luc reporter plasmid (coding for firefly luciferase), and after $24 \mathrm{~h}$ they were treated with $5 \mu \mathrm{M}$ HPR or $200 \mathrm{ng} / \mathrm{ml}$ TPA, or the two agents together, for $24 \mathrm{~h}$. The cells were harvested and analyzed for luciferase activity. The data were normalized to the activity of the Renilla luciferase coded by the cotransfected control pRL plasmid. Luciferase activities were calculated as relative activities by arbitrarily setting the activity of untreated cells at 1 . Data represent the means \pm S.E.M. of triplicate determinations cells were transfected with a plasmid containing the luciferase reporter gene driven by a basic promoter element joined to tandem repeats of AP-1 binding elements. At $24 \mathrm{~h}$ after transfection, the cells were treated with $5 \mu \mathrm{M}$ HPR or $200 \mathrm{ng} /$ $\mathrm{ml}$ 12-tetradecanoylphorbol 13-acetate (TPA), or the two agents together, for $24 \mathrm{~h}$, and luciferase activity was measured (Figure 8). TPA treated cells showed an approximately 2.5 -fold enhanced luciferase activity compared to untreated cells. HPR treatment caused a three-fold increase in luciferase activity and it was able to potentiate by approximately seven-fold the luciferase activity induced by TPA. Such results supported the hypothesis that AP-1 is involved in the cellular response of A2780 cells to HPR.

\section{Effect of cell transfection with a dominant-negative Fos gene on HPR response}

To confirm the involvement of AP-1 in HPR response, A2780 cells were transfected with a vector expressing an AP-1 dominant negative (designated as A-Fos) that abolishes AP-1 DNA binding and inhibits its activity. ${ }^{33,34}$ After transfection, the cells were selected for their ability to grow in medium containing geneticin, and the isolated resistant clones were analyzed for expression of the exogenous A-Fos mRNA by Northern hybridization. Figure 9a reports the results of three representative clones (cl.1, cl.2, and cl.3). Hybridization with the DNA, coding for A-Fos, detected in the three clones a band of approximately $300 \mathrm{bp}$, corresponding to the exogenous A-Fos mRNA, which was absent in cells transfected with the empty vector. The levels of A-Fos mRNA in cl. 1 were much higher than in cl.2 and cl.3. The growth inhibitory effect of HPR was evaluated in A-Fos-transfected clones, estimating cell number after $3 \mu \mathrm{M}$ HPR treatment for $72 \mathrm{~h}$. Growth rates of untreated A-Fos-expressing cells were similar to those of cells transfected with the empty vector (data not shown). However, the sensitivity to HPR of A-Fos-expressing clones was lower than that of $A 2780$ cells transfected with the empty vector (Figure 9b). cl.1, which had the highest overexpression of A-Fos, showed the strongest decrease in sensitivity to HPR. Also $\mathrm{cl} .2$ and $\mathrm{cl} .3$, which only slightly
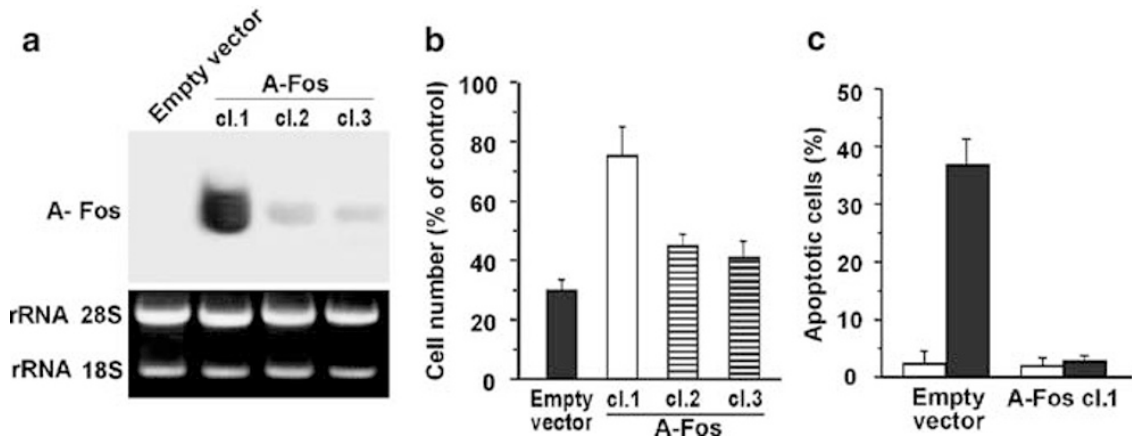

Figure 9 Reduced HPR growth inhibition and apoptosis in A2780 cells stably transfected with A-Fos. (a) Northern blot analysis for A-Fos expression in A2780 transfected clones and in A2780 control cells (empty vector). Transfected clones were harvested, and total cellular RNA was analyzed for expression of the exogenous cDNA. As a control for loading, 18S-28S rRNA was stained with ethidium bromide. (b) Growth inhibitory effect of HPR on A2780 A-Fos transfected clones and on control cells. Cells were treated with $3 \mu \mathrm{M}$ HPR $24 \mathrm{~h}$ after seeding, and surviving cell number was evaluated 3 days later. Data represent the means \pm S.D. of three independent experiments. (c) Detection of HPR-induced apoptosis in A2780 A-Fos cl.1 and in control cells. At 1 day after seeding, the cells were treated with $3 \mu \mathrm{M} \mathrm{HPR}$ (black columns) or DMSO (white columns) for $72 \mathrm{~h}$, and apoptosis was evaluated by the TUNEL assay. Data represent the means \pm S.D. of two independent experiments 
expressed A-Fos mRNA, showed slightly reduced sensitivity to HPR. Analysis of apoptosis on cl.1, the clone with the highest A-Fos expression, revealed no HPR-induced apoptosis, contrary to that observed in the clone carrying the empty vector (Figure 9c). Thus, the results demonstrated that AP-1 is involved in HPR antiproliferative and apoptotic effects in A2780 cells.

\section{Discussion}

Investigation of the involvement of the proto-oncogene c-Fos in apoptosis induced by HPR in ovarian cancer cells provided direct evidence of such a role. We demonstrated that in A2780, a human ovarian carcinoma cell line sensitive to the apoptotic effect of the retinoid, HPR-induced apoptosis is accompanied by elevation of c-Fos at mRNA and protein levels. In contrast, the increase in c-Fos expression was not observed when HPR-resistant cells (A2780/HPR), developed by continuous in vitro exposure to HPR of A2780 cells, ${ }^{29}$ were treated with HPR. In other human ovarian cancer cell lines (SKOV-3, OVCA-432, OAW-42, and IGROV-1), which required for growth inhibition higher HPR doses than A2780 cells, c-Fos upregulation occurred but only at high effective doses of HPR. The association between the apoptosis promoted by HPR and c-Fos upregulation thus suggested a role for c-Fos as a possible mediator of HPR effects. The hypothesis of c-Fos involvement in HPR-induced apoptosis was also supported by the fact that c-Fos expression was selectively upregulated by HPR but not by RA and 13-cis-RA, which failed to inhibit the growth in A2780 cells. ${ }^{29}$

There have been many reported instances of increased cFos levels in association with apoptosis induced by drugs and chemical agents in various cell types. ${ }^{24}$ Interestingly, the involvement of c-Fos has also been suggested in retinoidinduced apoptosis. In fact, the synthetic retinoid CD437 (6-(-2naphthalene carboxylic acid), a potent inducer of apoptosis, was shown to upregulate c-Fos expression in tumor cells of different types such as melanoma, ${ }^{35}$ head and neck, ${ }^{36}$ and prostate cancer. ${ }^{37}$ In HPR-treated A2780 cells, c-Fos mRNA level was not modified at $6 \mathrm{~h}$, but it was upregulated within $24 \mathrm{~h}$ and it continued to increase for a prolonged period of time $(48 \mathrm{~h})$. The c-Fos expression profile that we described here, that is a late and sustained induction, is different from the cFos induction profiles described with other apoptotic-inducing agents as rapid and transient. ${ }^{38-40}$ Apoptosis-inducing compounds, such as quercetin, ${ }^{38}$ mercury chloride, ${ }^{39}$ and vitamin $\mathrm{K}_{3},{ }^{40}$ cause an increase in c-Fos mRNA within 15-60 min that returns to basal levels within $2 \mathrm{~h}$. Interestingly, c-Fos upregulation by treatment with the retinoid CD437 could be detected only after prolonged treatment of melanoma cells with the drug, that is at 24 and $48 \mathrm{~h} .{ }^{35}$ Also in prostate cancer cells, CD437 treatment caused a sustained c-Fos upregulation for $32 \mathrm{~h}$ even though it could already be detected after $4 \mathrm{~h}$ of treatment. ${ }^{37}$

Overall, such results indicate that enhanced and prolonged expression of c-Fos may be a relevant event for retinoidinduced apoptosis in a variety of cell types. However, the mechanisms through which retinoids enhance c-Fos expres- sion levels have not been elucidated. In accord with the observed effect of HPR on c-Fos, we recently showed that HPR was able to induce a dose- and time-dependent increase in cellular ceramide levels in A2780 cells, whereas such an effect was not observed in A2780/HPR cells. ${ }^{22}$ Since induction of c-Fos expression due to ceramide treatment has been reported in different cell systems, ${ }^{30-32}$ we hypothesized that HPR-induced elevation of ceramide levels in A2780 cells might be responsible for c-Fos induction. According to our hypothesis, treatment of A2780 cells with C2Cer caused upregulation of c-Fos mRNA expression. In addition, cotreatment of A2780 cells with HPR and the ceramide synthase inhibitor $\mathrm{FB}_{1}$ reduced $\mathrm{HPR}$-induced upregulation of c-Fos expression and caused a reduction of HPR-induced apoptosis.

A causal relationship between upregulation of c-Fos expression and apoptosis induction was established by overexpression of c-Fos in A2780 cells. c-Fos-transfected cells, in the absence of external stimuli, exhibited reduced growth ability and increased apoptosis rate, thus demonstrating a role of c-Fos in actively inducing apoptosis in these cells. Even though a functional involvement of c-Fos in apoptosis has been described, ${ }^{25,41,42}$ the mechanism(s) by which c-Fos contributes to apoptosis is poorly understood. Some studies have shown that apoptosis accompanied by elevated c-Fos expression is associated to a concomitant activation of AP-1 transcription factor. ${ }^{35,43,44}$ The activity of AP-1 has been associated mainly with cell proliferation and tumor progression, but there is increasing evidence that AP-1 is also implicated in cell death. ${ }^{23}$

The ability of AP-1 to be involved in several different cellular processes requires that $\mathrm{AP}-1$ activates different target genes under different conditions. AP-1 is not a single transcription factor, but instead a series of related dimeric complexes of Fos and Jun families. It is likely that changes in the composition of AP-1 are instrumental in mediating cellular response to different stimuli. Interestingly, involvement of AP1 has also been reported in retinoid-induced apoptosis in tumor cells of different histotypes. A role for AP-1 has been demonstrated in CD437-induced apoptosis in human melanoma and lung cancer cells, ${ }^{35,45}$ and in RA-induced growth inhibition in mouse melanoma cells. ${ }^{43}$ Hence, we hypothesized that in A2780 cells c-Fos carried out its proapototic action as a member of AP-1 in response to HPR. We first analyzed c-Jun expression in response to HPR treatment because the product of the proto-oncogene is one of the main dimerization partners of $c-F o s$ within AP-1. Similarly to that observed for $\mathrm{c}$-Fos expression, HPR treatment increased cJun expression only in sensitive cells, thus suggesting AP-1 involvement in HPR-induced apoptosis. Interestingly, it has been recently reported that c-Jun $\mathrm{NH}_{2}$-terminal kinase (JNK) activation plays an important role in the execution of HPRinduced apoptosis in the androgen-sensitive prostate cancer cell line LNCaP. ${ }^{46}$ Moreover, in these cells, testosterone enhanced HPR-induced apoptosis by activating AP-1 and by inducing c-Jun expression. We have not assessed the role of JNK activation by HPR. However, the results in prostate cancer cells and our results suggest that the induction of c-Jun expression/phosphorylation plays an important role in mediating HPR effects. 
Our initial findings prompted us to investigate the effect of HPR on AP-1 activity. It has been extensively documented that retinoids interact with the AP-1 signal transduction pathway, and anti-AP-1 activity has been mainly reported. ${ }^{47}$ In A2780 cells, we showed that HPR treatment increased AP1 transcriptional activity and potentiated the AP-1 activity induced by TPA. Contrary to our observations, it has been reported that HPR, in HeLa cells, showed anti-AP-1 activity (transrepression) and inhibited TPA-induced AP-1 activity. ${ }^{13}$ It is noteworthy that in HeLa cells, HPR transrepression activity was observed only in RAR- and RXR-overexpressing cells, whereas such an effect was not detected in the absence of transfected receptors. ${ }^{13}$ In our study in A2780 cells, the effect of HPR on AP-1 transactivation was observed in the absence of exogenous receptors. The different findings observed in the two experimental conditions suggest that HPR might have different effects on AP-1 activity depending on RAR and RXR expression. Interactions between RARs and RXRs and AP-1 components, as well as the involvement of other factor, may account for the cell type specificity of these opposite effects. AP-1 involvement in mediating the HPR effect in A2780 cells was further confirmed by using a dominant-negative c-Fos gene (A-Fos), which inhibits AP-1 DNA binding. ${ }^{33,34}$ Transfection with A-Fos was found to decrease sensitivity to the growth inhibitory effect of HPR and to prevent HPR-induced apoptosis in A2780 cells, indicating that HPR may exert its activities through activation of AP-1. Similar findings have been reported for two other unrelated retinoids, CD437 and RA. Inhibition of AP-1 activity by transfection of a dominantnegative c-Jun was found to prevent apoptosis induction by CD437 in lung carcinoma cells, ${ }^{45}$ and transfection of a dominant-negative c-Fos decreased RA sensitivity ${ }^{43}$ in mouse melanoma cells.

In summary, this report documents that in ovarian carcinoma cells sensitive to HPR growth inhibitory effects, HPR treatment resulted in induction of c-Fos and c-Jun expression and in increased AP-1 activity. The overexpression of c-Fos caused an increase in apoptosis, whereas expression of a dominant-negative c-Fos gene protected the cells against HPR-induced apoptosis. These results demonstrate for the first time an important role for C-Fos and AP-1 in mediating HPR-induced apoptosis, although additional studies are needed to assess the molecular mechanisms of these molecules in apoptosis induction.

\section{Materials and methods}

\section{Cell culture conditions and drugs}

The human ovarian carcinoma cell lines A2780, obtained from Dr. Ozols (Bethesda, MD, USA), IGROV-1, obtained from Dr. Bénard (Villejuif, France), OVCA-432, obtained from Dr. Knapp (Boston, MA, USA), and SKOV-3, purchased from ATCC (Manassas, VA, USA), were grown in monolayer in RPMI 1640 medium containing 10\% fetal bovine serum in $5 \% \mathrm{CO}_{2}$ at $37^{\circ} \mathrm{C}$. The human ovarian carcinoma cell line OAW-42, obtained from DKFZ (Germany), was grown in monolayer in MEM medium containing $10 \%$ fetal bovine serum. The generation of A2780/HPR cells, resistant to HPR, has already been described.$^{29} \mathrm{HPR}$ was kindly provided by Dr. Crowell (National Cancer Institute), and RA and 13-cis RA were purchased from Sigma (St. Louis, MO, USA). HPR, RA and 13-cis RA were dissolved at $10 \mathrm{mM}$ in DMSO prior to further dilution in culture medium and stored at $-80^{\circ} \mathrm{C}$ in the dark. C2Cer was a kind gift of Dr. Prinetti (Milan, Italy). FB 1 (Sigma) was dissolved at $10 \mathrm{mg} / \mathrm{ml}$ in methanol prior to further dilution in culture medium. TPA (Sigma) was dissolved in DMSO at $250 \mu \mathrm{g} / \mathrm{ml}$ and frozen until use.

\section{Growth inhibition assay}

Cells were seeded at a density of 3500 cells per well in 96 cluster tissue culture plates, treated the next day with different concentrations of HPR, and incubated for the indicated times. Control cultures received the same amount of DMSO as the treated cultures $(0.1 \%)$. Cell number was estimated by using the sulforhodamine B assay. ${ }^{48}$ Three analyses were performed, and four replicate wells were used for each analysis.

\section{Apoptosis assays}

Apoptotic cells were identified by analysis of nuclear morphology, by detection of single-strand breaks in DNA, or by quantization of the amount of cytoplasmic histone-associated DNA fragments. For nuclear morphology staining, $15 \mu \mathrm{g} / \mathrm{ml}$ Hoechst 33342 (Sigma) was added to the cell culture medium, and the cells were incubated for $1 \mathrm{~h}$ at $37^{\circ} \mathrm{C}$, harvested, washed twice in phosphate-buffered saline (PBS) and fixed in $2 \%$ paraformaldehyde for $1 \mathrm{~h}$ at $26^{\circ} \mathrm{C}$. Nuclear morphology, assessed on at least 200 cells in two different smears, was examined with a fluorescent microscope, and cells with condensed and fragmented nuclei were identified and scored as apoptotic cells. For DNA fragmentation analysis, an in situ cell death detection kit (Roche Diagnostics, Mannheim, Germany) based on the TUNEL method was used. The assay was performed according to the manufacturer's instructions. Briefly, the harvested cells were washed twice in PBS, fixed in $2 \%$ paraformaldehyde for $1 \mathrm{~h}$ at $26^{\circ} \mathrm{C}$, and permeabilized with $0.1 \%$ Triton $\mathrm{X}-100$ and $0.1 \%$ sodium citrate in PBS. After washing, the cells were resuspended in a TUNEL reaction mixture containing fluorescein isothiocyanate-dUTP and terminal-deoxy-nucleotidyl-transferase and incubated for $1 \mathrm{~h}$ at $37^{\circ} \mathrm{C}$. The number of TUNEL-positive cells, as detected by fluorescent microscopy, was assessed on at least 200 cells in two different smears. For the determination of cytoplasmic histone-associated DNA fragments, the Cell Death Detection ELISA assay (Roche Diagnostics) was performed according to the manufacturer's instructions.

\section{Semiquantitative RT-PCR analysis}

For semiquantitative RT-PCR analysis, single-stranded CDNA was synthesized from $2 \mu \mathrm{g}$ of total cellular RNA isolated using the TriReagent method (Molecular Research Center, Cincinnati, OH, USA). The synthesis was performed by using $0.5 \mu \mathrm{g}$ of oligo(dT) (Gibco Brl, Paisley, UK), $200 \mathrm{U}$ of M-MLV reverse transcriptase (Gibco Brl), $4 \mu$ of $5 \times$ first-strand buffer (Gibco Brl), $0.1 \mathrm{M} \mathrm{1,4-dithiothreitol,} \mathrm{and} 10 \mathrm{mM}$ of each dNTP (Amersham, Arlington Heights, IL, USA) in a total volume of $20 \mu$ l. Reverse transcription was performed for $1 \mathrm{~h}$ at $37^{\circ} \mathrm{C}$; the samples were subsequently heated for $5 \mathrm{~min}$ at $95^{\circ} \mathrm{C}$ to terminate the reverse transcription reaction. Target (c-Fos or c-Jun) and control ( $\beta$-actin) gene sequences were coamplified in the same reaction using the following gene-specific oligonucleotide primers: $c$ Fos forward primer, 5'-ATGTTCTCGGGCTTCAACGCAGACTAC-3'; cFos reverse primer, 5'-GTACAGGAAGCCTCTAGGGAAGATGTG-3'; cJun forward primer, $5^{\prime}$-TCCTTAAGAACACAAAGCGG-3'; c-Jun reverse primer, $5^{\prime}$-AAACAACACTGGGCAGGATA-3'; $\beta$-actin forward primer, $5^{\prime}$ GAAATCGTGCGTGACATTAAG-3'; $\beta$-actin reverse primer $5^{\prime}$-CTAGAAGCATTTGCGGTGGACGATGGAGGGGCC-3'. On the basis of their 
sequences, the expected PCR product sizes from these sets of primers are $1239 \mathrm{bp}$ for $\mathrm{c}$-Fos, $230 \mathrm{bp}$ for c-Jun, and $509 \mathrm{bp}$ for $\beta$-actin. In total, $5 \mu \mathrm{l}$ of the retrotranscription reaction (diluted to $100 \mu \mathrm{l}$ ) was used in a final volume of $50 \mu \mathrm{l}$ for the PCR reaction, which contained $1 \times$ PCR buffer, $1.5 \mathrm{mM} \mathrm{MgCl}_{2}, 200 \mu \mathrm{M}$ of each dNTP, $10 \mathrm{pmol}$ of each primer, and $0.5 \mathrm{U}$ Amplitaq DNA polymerase (Applied Biosystems, Foster City, CA, USA). The amplification reaction was initiated by incubation of PCR samples at $94^{\circ} \mathrm{C}$ for $2 \mathrm{~min}$, followed by a cyclic program at $94^{\circ} \mathrm{C}$ for $30 \mathrm{~s}, 55^{\circ} \mathrm{C}$ for $45 \mathrm{~s}$ and $72^{\circ} \mathrm{C}$ for $45 \mathrm{~s}$ for $\mathrm{C}$-Fos and at $94^{\circ} \mathrm{C}$ for $30 \mathrm{~s}, 52.5^{\circ} \mathrm{C}$ for $45 \mathrm{~s}$ and $72^{\circ} \mathrm{C}$ for $45 \mathrm{~s}$ for c-Jun. For each primer set, an increasing number of PCR cycles was performed with otherwise fixed conditions to determine the optimal number of cycles to be used. The number of cycles was 35 for cFos amplification, 40 for c-Jun, and 20 for $\beta$-actin. The PCR products $(15 \mu \mathrm{l})$ were subjected to electrophoresis in agarose gel and visualized by UV after ethidium bromide staining.

\section{Northern blot analysis}

About $20 \mu \mathrm{g}$ of total RNA was fractionated in $1 \%$ agarose gel in $0.66 \mathrm{M}$ formaldehyde, transferred to Hybond $\mathrm{N}+$ nylon membrane (Amersham), and probed with ${ }^{32} \mathrm{P}$-labeled $\mathrm{A}$-Fos DNA fragment. The probe was labeled with $\left[\alpha^{-}{ }^{32} \mathrm{P}\right] \mathrm{dCTP}$ (ICN, Costa Mesa, CA, USA) to a specific activity of approximately $2 \times 10^{9} \mathrm{cpm} / \mu \mathrm{g}\left(>10^{6} \mathrm{cpm} / \mathrm{ml}\right)$ by the Prime-it II Random Primer Labeling Kit (Stratagene, La Jolla, CA, USA). Following hybridization for $3-12 \mathrm{~h}$ at $65^{\circ} \mathrm{C}$ in Rapid-Hyb buffer (Amersham), the blots were washed twice with $2 \times \mathrm{SSC} / 0.1 \%$ sodium dodecyl sulfate (SDS) at room temperature for $10 \mathrm{~min}$. The final washes were done with $0.1 \times \mathrm{SSC} / 0.1 \%$ sodium dodecyl sulfate at $64^{\circ} \mathrm{C}$ for $20 \mathrm{~min}$ for at least two times. Membranes were exposed to X-ray film (Hyperfilm-MP, Amersham) using double-intensifying screens.

\section{Construction of expression vectors}

The human c-Fos full-length CDNA was cloned into the eucaryotic expression vector pREP4 (Invitrogen) containing the Rous sarcoma virus long terminal repeat enhancer/promoter and the hygromycin-B-resistance gene needed for selection of transfected cells. For this purpose, the cDNA of c-Fos inserted in pBK28 plasmid (obtained from Dr. Paul Chiao, University of Texas, MD Anderson Cancer Center, Houston, TX, USA) was released by double digestion with $E c o R I$ and $X$ hol restriction enzymes and ligated into the EcoRl/Xhol sites of pBluescript SK plasmid (Stratagene). The resulting recombinant product was then doubledigested with BamHI and Xhol, and c-Fos CDNA was subcloned into the BamHI/Xhol sites of pREP4 plasmid.

$c$-Fos was transiently expressed as a fusion protein with the GFP fused to its $\mathrm{C}$-terminal. c-Fos coding the cDNA region deprived of the stop codon was obtained by PCR amplification from the pBK28 plasmid containing the full-length CDNA encoding human c-Fos. We used the forward oligonucleotide primer 5'-TACCGCTCGAGCCACCATGATGTTCTCGGGCTTC-3' (which contains an Xhol restriction site and a Kozak sequence (CCACC)) and the reverse oligonucleotide primer $5^{\prime}$ CGCGGATCCAGGGCCAGCAGCGTGGGT-3' (which contains a BamHI restriction site). The amplification reaction was initiated by incubation of the sample at $94^{\circ} \mathrm{C}$ for $2 \mathrm{~min}$, followed by 15 cycles consisting of incubation at $94^{\circ} \mathrm{C}$ for $30 \mathrm{~s}$, at $45^{\circ} \mathrm{C}$ for $60 \mathrm{~s}$, and $68^{\circ} \mathrm{C}$ for $90 \mathrm{~s}$ and by 20 cycles at $94^{\circ} \mathrm{C}$ for $60 \mathrm{~s}$ and $68^{\circ} \mathrm{C}$ for $90 \mathrm{~s}$. The resultant PCR fragment was digested with $\mathrm{XhOl}$ and $\mathrm{BamHI}$ and ligated in frame with the GFP gene into the expression vector pEGFP-N1 (Clontech, Palo Alto, CA, USA), previously digested with the same enzymes.
The construct carrying the dominant-negative Fos gene, termed A-Fos, has been described elsewhere. ${ }^{33}$ Briefly, A-Fos consists of an acidic amphipathic protein sequence appended onto the $\mathrm{N}$-terminus of the c-Fos leucin zipper, thereby replacing the basic region critical for DNA binding that is able to inhibit AP-1 DNA binding.

\section{Transient and stable transfections}

Cells $\left(5 \times 10^{5}\right)$ were seeded in $60 \mathrm{~mm}$ dishes; $24 \mathrm{~h}$ later, a mixture of lipofectin reagent (Gibco Brl) and $2.5 \mu \mathrm{g}$ of expression plasmid was added and then incubated for $6 \mathrm{~h}$ in serum-free medium. Cells were then cultured in medium supplemented with serum for an additional $72 \mathrm{~h}$ prior to further analysis. In stable transfection, a medium containing hygromycin B (Roche Applied Science, Basel, Switzerland) at a concentration of $250 \mu \mathrm{g} / \mathrm{ml}$, or G418 (Gibco Brl) at a concentration of $400 \mu \mathrm{g} / \mathrm{ml}$, was used for the selection of transfectants.

\section{Immunoblot analysis}

Cells were lysed in Laemmli sample buffer containing $5 \% \quad \beta$ mercaptoethanol and boiled for $3 \mathrm{~min}$. Aliquots containing $80 \mu \mathrm{g}$ of total cell proteins were fractionated on 12\% SDS-PAGE and transferred to nitrocellulose membranes (Amersham). Membranes were blocked in 3\% nonfat milk in Tris-buffered saline for $20 \mathrm{~min}$ at room temperature and then incubated overnight at $4^{\circ} \mathrm{C}$ with rabbit polyclonal antibodies raised against human c-Fos (Upstate Biotechnology, NY, USA). After washing in Trisbuffered saline containing $0.1 \%$ Tween 20 , the filters were incubated with peroxidase anti-rabbit immunoglobulin $\mathrm{G}$, and specific complexes were revealed by chemiluminescence according to the enhanced chemiluminescence Western blotting detection system kit (Amersham).

\section{Measurement of AP-1 transactivation}

A2780 cells were seeded at a density of $2 \times 10^{5}$ cells per well in six-well plates. After $24 \mathrm{~h}$, cells were cotransfected with pAP1-Luc, a cis-reporter plasmid containing the firefly luciferase reporter gene driven by a basic promoter element joined to tandem repeats of AP-1 binding element (Stratagene), and with $\mathrm{pRL}$, a control plasmid constitutively expressing Renilla luciferase (Promega, Madison, WI, USA). A mixture of lipofectin reagent (Gibco Brl), $2.5 \mu \mathrm{g}$ of reporter plasmid, and $0.5 \mu \mathrm{g}$ of control plasmid was added, and plates were incubated for $6 \mathrm{~h}$ in serum-free medium. Cells were refed with medium supplemented with serum and after $24 \mathrm{~h}$ exposed to HPR and/or TPA for an additional $24 \mathrm{~h}$. Cells were lysed using passive lysis buffer (Promega), and luciferase activity was determined using the Dual Luciferase Reporter Assay (Promega) according to the manufacturer's instructions using a luminometer. Renilla luciferase activity was used as an internal control to normalize all results.

\section{Acknowledgements}

The study was supported by grants from the Associazione Italiana per la Ricerca sul Cancro, Milan, Italy.

\section{References}

1. Nagy L, Thomazy VA, Heyman RA and Davies PJ (1998) Retinoid-induced apoptosis in normal and neoplastic tissues. Cell Death Differ. 5: 11-19 
2. Lotan R (1996) Retinoids in cancer chemoprevention. FASEB J. 10: 1031-1039

3. Formelli F, Barua $A B$ and Olson JA (1996) Bioactivities of $\mathrm{N}$-(4hydroxyphenyl)retinamide and retinoyl beta-glucuronide. FASEB J. 10: 1014-1024

4. Supino $R$, Crosti M, Clerici $M$, Walters $A$, Cleris L, Zunino $F$ and Formelli $F$ (1996) Induction of apoptosis by fenretinide (4HPR) in human ovarian carcinoma cells and its association with retinoic acid receptor expression. Int. J. Cancer 65: 491-497

5. Pergolizzi R, Appierto V, Crosti M, Cavadini E, Cleris L, Guffanti A and Formelli F (1999) Role of retinoic acid receptor overexpression in sensitivity to fenretinide and tumorigenicity of human ovarian carcinoma cells. Int. J. Cancer 81: 829-834

6. Chiesa F, Tradati N, Marazza M, Rossi N, Boracchi P, Mariani, Clerici M, Formelli F, Barzan L, Carrassi A, Pastorini A, Camerini T, Giardini R, Zurrida S, Minn FL, Costa A, De Palo G and Veronesi U (1992) Prevention of local relapses and new localisations of oral leukoplakias with the synthetic retinoid fenretinide (4-HPR). Preliminary results. Oral Oncol. Eur. J. Cancer 2: 97-102

7. Tradati N, Chiesa F, Rossi N, Grigolato R, Formelli F, Costa A and De Palo G (1994) Successful topical treatment of oral lichen planus and leukoplakias with fenretinide (4-HPR). Cancer Lett. 76: 109-111

8. Moglia D, Formelli F, Baliva G, Bono A, Accetturi M, Nava M and De Palo G (1996) Effects of topical treatment with fenretinide (4-HPR) and plasma vitamin A levels in patients with actinic keratoses. Cancer Lett. 110: 87-91

9. De Palo G, Veronesi U, Camerini T, Formelli F, Mascotti G, Boni C, Fosser V, Del Vecchio M, Campa T, Costa A and Marubini E (1995) Can fenretinide protect women against ovarian cancer. J. Natl. Cancer Inst. 87: 146-147

10. De Palo G, Mariani L, Camerini T, Marubini E, Formelli F, Pasini B, Decensi A and Veronesi U (2002) Effect of fenretinide on ovarian carcinoma occurrence. Gynecol. Oncol. 86: 24-27

11. Veronesi U, De Palo G, Marubini E, Costa A, Formelli F, Mariani L, Decensi A, Camerini T, Del Turco MR, Di Mauro MG, Muraca MG, Del Vecchio M, Pinto C, D'Aiuto G, Boni C, Campa T, Magni A, Miceli R, Perloff M, Malone WF and Sporn MB (1999) Randomized trial of fenretinide to prevent second breast malignancy in women with early breast cancer. Natl. Cancer Inst. 91: 1847-1856

12. Swisshelm K, Ryan K, Lee X, Tsou HC, Peacocke M and Sager R (1994) Down-regulation of retinoic acid receptor $\beta$ in mammary carcinoma cell lines and its up-regulation in senescing normal mammary epithelial cells. Cell Growth Diff. 5: 133-141

13. Fanjul A, Delia D, Pierotti MA, Rideout D, Qiu J and Pfahl M (1996) 4-Hydroxyphenyl retinamide is a highly selective activator of retinoid receptors. J. Biol. Chem. 271: 22441-22446

14. Sabichi AL, Hendricks DT, Bober M and Birrer MJ (1998) Retinoic acid receptor $\beta$ expression and growth inhibition of gynecologic cancer cells by the synthetic retinoid N-(4-hydroxyphenyl)retinamide. J. Natl. Cancer Inst. 90: 597-605

15. Delia D, Aiello A, Meroni L, Nicolini M, Reed JC and Pierotti MA (1997) Role of antioxidants and intracellular free radicals in retinamide-induced cell death. Carcinogenesis 18: 943-948

16. Oridate N, Suzuki S, Higuchi M, Mitchell MF, Hong WK and Lotan R (1997) Involvement of reactive oxygen species in $\mathrm{N}$-(4-hydroxyphenyl)retinamideinduced apoptosis in cervical carcinoma cells. J. Natl. Cancer Inst. 89: 1191-1198

17. Hail Jr N and Lotan R (2001) Mitochondrial respiration is uniquely associated with the prooxidant and apoptotic effects of $\mathrm{N}$-(4-hydroxyphenyl)retinamide. J. Biol. Chem. 276: 45614-45621

18. You KR, Wen J, Lee ST and Kim DG (2002) Cytochrome Coxidase subunit III: a molecular marker for $\mathrm{N}$-(4-hydroxyphenyl)retinamide-induced oxidative stress in hepatoma cells. J. Biol. Chem. 277: 3870-3877

19. Delia D, Aiello A, Formelli F, Fontanella E, Costa A, Miyashita T, Reed JC and Pierotti MA (1995) Regulation of apoptosis induced by the retinoid $\mathrm{N}-(4$ hydroxyphenyl)retinamide and effect of deregulated bcl-2. Blood 85: 359-367

20. Wang H, Maurer BJ, Reynolds CP and Cabot MC (2001) N-(4hydroxyphenyl)retinamide elevates ceramide in neuroblastoma cell lines by coordinate activation of serine palmitoyltransferase and ceramide synthase. Cancer Res. 61: 5102-5105

21. Panigone S, Bergomas R, Fontanella E, Prinetti A, Sandhoff K, Grabowski GA and Delia D (2001) Up-regulation of prosaposin by the retinoid HPR and its effect on ceramide production and integrin receptors. FASEB J. 15: 1475-1477
22. Prinetti A, Basso B, Appierto V, Villani MG, Valsecchi M, Loberto N, Prioni S, Chigorno V, Cavadini E, Formelli F and Sonnino S (2003) Altered sphingolipid metabolism in $\mathrm{N}$-(4-hydroxyphenyl)retinamide-resistant A2780 human ovarian carcinoma cells. J. Biol. Chem. 278: 5574-5583

23. Shaulian E and Karin M (2001) AP-1 in cell proliferation and survival. Oncogene 20: $2390-2400$

24. Teng CS (2000) Protooncogenes as mediators of apoptosis. Int. Rev. Cytol. 197: 137-202

25. Preston GA, Lyon TT, Yin Y, Lang JE, Solomon G, Annab L, Srinivasan DG, Alcorta DA and Barrett JC (1996) Induction of apoptosis by c-Fos protein. Mol. Cell. Biol. 16: 211-218

26. Hu L, Hatano M, Ruther U and Tokuhisa T (1996) Overexpression of c-Fos induces apoptosis of CD43+ pro-B cells. J. Immunol. 157: 3804-3811

27. Liebermann DA, Gregory B and Hoffman B (1998) AP-1 (Fos/Jun) transcription factors in hematopoietic differentiation and apoptosis. Int. J. Oncol. 12: $685-700$

28. Jochum W, Passegue E and Wagner EF (2001) AP-1 in mouse development and tumorigenesis. Oncogene 20: 2401-2412

29. Appierto V, Cavadini E, Pergolizzi R, Cleris L, Lotan R, Canevari S and Formelli $F$ (2001) Decrease in drug accumulation and in tumour aggressiveness marker expression in a fenretinide-induced resistant ovarian tumour cell line. Br. J. Cancer 84: 1528-1534

30. Kim BC and Kim JH (1998) Exogenous C2-ceramide activates c-fos serum response element via Rac-dependent signalling pathway. Biochem. J. 330: 1009-1014

31. Kondo T, Matsuda T, Kitano T, Takahashi A, Tashima M, Ishikura H, Umehara H, Domae N, Uchiyama T and Okazaki T (2000) Role of c-jun expression increased by heat shock- and ceramide-activated caspase-3 in HL-60 cell apoptosis. Possible involvement of ceramide in heat shock-induced apoptosis. J. Biol. Chem. 275: 7668-7676

32. Willaime $\mathrm{S}$, Vanhoutte $\mathrm{P}$, Caboche $\mathrm{J}$, Lemaigre-Dubreuil $\mathrm{Y}$, Mariani $\mathrm{J}$ and Brugg B (2001) Ceramide-induced apoptosis in cortical neurons is mediated by an increase in p38 phosphorylation and not by the decrease in ERK phosphorylation. Eur. J. Neurosci. 13: 2037-2046

33. Olive M, Krylov D, Echlin DR, Gardner K, Taparowsky E and Vinson C (1997) A dominant negative to activation protein-1 (AP1) that abolishes DNA binding and inhibits oncogenesis. J. Biol. Chem. 272: 18586-18594

34. Vinson C, Myakishev M, Acharya A, Mir AA, Moll JR and Bonovich M (2002) Classification of human B-ZIP proteins based on dimerization properties. Mol. Cell. Biol. 22: 6321-6335

35. Schadendorf D, Kern MA, Artuc M, Pahl HL, Rosenbach T, Fichtner I, Nurnberg W, Stuting S, von Stebut E, Worm M, Makki A, Jurgovsky K, Kolde G and Henz BM (1996) Treatment of melanoma cells with the synthetic retinoid CD437 induces apoptosis via activation of AP-1 in vitro and causes growth inhibition in xenografts in vivo. J. Cell Biol. 135: 1889-1898

36. Sun SY, Yue P, Chandraratna RA, Tesfaigzi Y, Hong WK and Lotan R (2000) Dual mechanisms of action of the retinoid CD437: nuclear retinoic acid receptor-mediated suppression of squamous differentiation and receptorindependent induction of apoptosis in UMSCC22B human head and neck squamous cell carcinoma cells. Mol. Pharmacol. 58: 508-514

37. Sun SY, Yue P and Lotan R (2000) Implication of multiple mechanisms in apoptosis induced by the synthetic retinoid $\mathrm{CD} 437$ in human prostate carcinoma cells. Oncogene 19: 4513-4522

38. Iwao K and Tsukamoto I (1999) Quercetin inhibited DNA synthesis and induced apoptosis associated with increase in c-fos mRNA level and the up-regulation of p21WAF1CIP1 mRNA and protein expression during liver regeneration after partial hepatectomy. Biochim. Biophys. Acta 1427: 112-120

39. Matsuoka M, Wispriyono B and Igisu H (1997) Induction of c-fos gene by mercury chloride in LLC-PK1 cells. Chem. Biol. Interact. 108: 95-106

40. Wu FY, Chang NT, Chen WJ and Juan CC (1993) Vitamin K3-induced cell cycle arrest and apoptotic cell death are accompanied by altered expression of c-fos and c-myc in nasopharyngeal carcinoma cells. Oncogene 8: 2237-2244

41. Mils V, Piette J, Barette C, Veyrune J, Tesniere A, Escot C, Guilhou JJ and Basset-Seguin N. (1997) The proto-oncogene c-fos increases the sensitivity of keratinocytes to apoptosis. Oncogene 14: 1555-1561

42. Smeyne RJ, Vendrell M, Hayward M, Baker SJ, Miao GG, Schilling K, Robertson LM, Curran T and Morgan JI (1993) Continuous c-Fos expression precedes programmed cell death in vivo. Nature 363: 166-169 
43. Huang $Y$, Boskovic $G$ and Niles RM (2002) Retinoic acid-induced AP-1 transcriptional activity regulates B16 mouse melanoma growth inhibition and differentiation. J. Cell. Physiol. 194: 162-170

44. Schaerli $P$ and Jaggi $R$ (1998) EGF-induced programmed cell death of human mammary carcinoma MDA-MB-468 cells is preceded by activation AP-1. Cell. Mol. Life Sci. 54: 129-138

45. Li Y, Lin B, Agadir A, Liu R, Dawson MI, Reed JC, Fontana JA, Bost F, Hobbs PD, Zheng Y, Chen GQ, Shroot B, Mercola D and Zhang XK (1998) Molecular determinants of AHPN (CD437)-induced growth arrest and apoptosis in human lung cancer cell lines. Mol. Cell. Biol. 18: 4719-4731
46. Shimada K, Nakamura M, Ishida E, Kishi M and Konishi N (2003) Requirement of $\mathrm{c}$-jun for testosterone-induced sensitization to $\mathrm{N}$-(4-hydroxyphenyl) retinamide-induced apoptosis. Mol. Carcinog. 36: 115-122

47. Altucci $L$ and Gronemeyer $H$ (2001) The promise of retinoids to fight against cancer. Nat. Rev. Cancer 1: 181-193

48. Monks A, Scudiero D, Skehan P, Shoemaker R, Paull K, Vistica D, Hose C, Langley J, Cronise P, Vaigro-Wolff A, Gray-Goodrich M, Campbell H, Mayo J and Boyd MR (1991) Feasibility of a high-flux anticancer drug screen using a diverse panel of cultured human tumor cell lines. J. Natl. Cancer Inst. 11: $757-766$ 